\title{
The levels of utilization of visual inspection screening of cervical cancer in Kitui, Kenya
}

\author{
Mwangi $\mathrm{JH}^{1}$, Gachau $\mathrm{AG}^{2}$, Kabiru EW ${ }^{3}$
}

\section{${ }^{1}$ Department of Community Health, School of Public Health, Kenyatta University, Nairobi, Kenya ${ }^{2}$ Department of Pathology, School of Medicine, Kenyatta University, Nairobi, Kenya \\ ${ }^{3}$ School of Public Health, Kenyatta University, Nairobi, Kenya}

Corresponding author: Dr. A.G. Gachau, Department of Pathology, School of Medicine, Kenyatta University, P.O. Box 43844 - 00100, Nairobi, Kenya. Email: gachau.albert@ku.ac.ke

\section{Abstract}

Background: Cervical cancer is a disease of public health importance with a high global morbidity and mortality. More than 266,000 women die every year, with $87 \%$ of them coming from low and middle-income countries. These are the areas where programmes for screening and treatment are either deficient or underutilized. The morbidity and the mortality rates remain high in Kenya despite the screening and treatment services that the Ministry of Health has rolled out all over the country. Low levels of utilization of the established screening systems leads to increased morbidity and mortality. The problem is more prevalent in the rural Kenya where socioeconomic status of the majority in the population is low. Kitui County is such a rural region in Kenya.

Objective: To determine the factors influencing the levels of utilization of the Visual Inspection method (VIA/VILI) for cervical cancer screening services in Kitui County, Kenya.

Methodology: This was a descriptive study involving 370 women of reproductive age attending public $\mathrm{MCH} /$ FP clinics in Kitui County Kenya. Systematic random sampling method was used to select the participants. Exit interview was the main data collection technique. Key informants were also interviewed and facilities' preparedness to provide adequate screening services was assessed using a facility survey checklist.

Results: A total of 370 women were interviewed, $69.2 \%$ of whom were aged below 29 years, $68 \%$ were married, $75 \%$ had three or fewer children, $19 \%$ did not have the basic level of formal education and $61 \%$ were earning less than 50 US\$ per month. The level of awareness on cervical cancer and its prevention was $53.8 \%$, with significant difference in relation to VIA/VILI utilization (OR $3.0675 \mathrm{p}=0.000$ ). Significance difference was also observed in cervical cancer testing and level of education $\left(\mathrm{X}^{2}=21.728\right.$, $\mathrm{df}=3, \mathrm{P}=0.000$ ), the main source of income, $\left(\mathrm{X}^{2}=15.030, \mathrm{df}=2, \mathrm{P}=0.01\right)$, average monthly income, $\left(X^{2}=27.942\right.$, $\mathrm{df}=4, \mathrm{P}=0.0001)$ and the main decision maker in the family, $\left(X^{2}=6.908, d f=2\right.$, $\mathrm{p}=0.032$ ). Public health facilities were not adequately equipped and well staffed to provide the VIA/VILI screening services.

Conclusion: Low levels (53.8\%) of awareness about cervical cancer and its prevention among eligible clients in Kitui Central Sub-county Kenya, which was below the national target of over $70 \%$, low coverage of health facilities and shortage of manpower lead to low levels of VIA/VILI screening. Therefore, there is a need to strengthen the existing services and interventions strategies, and enhance cancer awareness campaigns in order to reduce the incidence of the disease.

Key words: Cervical cancer, VIA/VILI, Screening, Awareness

\section{Introduction}

Cervical cancer is the fourth commonest cancer in women and the seventh overall, with global estimates of 528,000 new cases every year [1] in which $85 \%$ of the burden occurs in the developing countries, accounting for almost $12 \%$ of all female cancers [2]. In East and Central Africa, cervical cancer remains the most common cancer in women accounting for $7.5 \%$ of all female cancers [3]. Mortality is high where the programmes for screening and treatment are either deficient and/or underutilized [3]. The condition affects the younger age group (less than 25 years) as a result of early sexual activities, multiple sexual partners and history of sexually transmitted diseases [4].

In Kenya, cervical cancer kills more women than any other cancer. This is a huge burden to the women population, the affected families, the community and the health care systems especially in 
poor, rural areas [5]. Data from hospital based registries in Kenya indicated that cervical cancer accounted for 70$80 \%$ of all cancers of the genital tract and $8-20 \%$ for all the cancer cases [6]. The number of women at risk of cervical cancer is estimated at 10.32 million in Kenya. The annual number of cervical cancer cases is 4,802 women with an average of 2,451 deaths.

Without intervention, the projected number of new cervical cancer cases in 2025 is 7,933 women and an annual death rate of 4,063 women. WHO/ICO (2010) gave a crude estimate of incidence rates $12.7 \%$ per 100,000 populations per year for cervical cancer [4]. Such high incidence is attributed to late diagnosis since most of the affected women visit the hospital late when the condition is already advanced and invasive [7]. Data from Kitui Sub-county Hospital gynaecological ward shows that there are at least two cases of confirmed cervical cancer lesions every month in women between the ages of 20 to 50 years [6]. In most cases the services for screening and treatment are deficient and/or underutilized where the facilities are available [4].

Visual inspection (VIA/VILI) methods for cervical cancer screening were introduced in 2005 in Kenya but the services were introduced in selected districts from 2007 [7]. Kitui County started offering the services in 2009. The coverage was less than $15 \%$ in 2013 against the national target of $70 \%$ [6]. National program for prevention of cancers of the cervix in which visual inspection tests are being implemented have not been reviewed and there is limited official documentation on the program processes since its inception in 2005.

The objective of the study was to determine the factors influencing the levels of utilization of the Visual Inspection method (VIA/VILI) in cervical cancer screening services in Kitui Central Sub-county, Kenya.

\section{Materials and Methods}

Site of study: The setting for this study was the MCH/FP clinics (public health facilities) in Kitui County in Eastern region of Kenya. It was a cross-sectional, descriptive analytical study in design involving one county hospital, six health centres and nineteen dispensaries distributed within a rural setting of the County. Questionnaire interviews were administered to 370 randomly selected women attending $\mathrm{MCH} / \mathrm{FP}$ clinics in the selected public health facilities. The key informants who were the heads of the facilities provided primary as well as secondary information about the facilities

Data was analyzed using SPSS Version 20. Crosstabulations were done and associations were established by Chi-square $\left(\mathrm{X}^{2}\right)$. Inferential statistics (P-value, confidence intervals, $\mathrm{X}^{2}$ ) was used to establish factors that predicted VIA/VILI services uptake. Logistic regression analysis was performed to further test variables that were statistically significant.

\section{Results}

Social demographic characteristics: Data for 370 women aged 20-49 years indicated that $55.1 \%$ of the women in the study group were between 20-29 years old, $68.1 \%$ were married and $75.9 \%$ had 3 children or less. The level of education was; $7.6 \%$ tertiary level, $55.7 \%$ had completed their basic formal education. For socioeconomic status, majority of the women $(61.4 \%)$ depended on farm produce, $51.9 \%$ depended on their partner as the income earner where $60.8 \%$ were earning US $\$ 50$ or less per month. The level of education was the only social demographic variable that had a significant statistical association with utilization of VIA/VILI screening (Table 1).

Table 1: The association of respondent's social demographic/economic characteristics and the level of utilization of screening services for cervical cancer

\begin{tabular}{|c|c|c|c|c|}
\hline Variables $(n=370)$ & $\begin{array}{l}\text { Screened } \\
\text { No. }(\%)\end{array}$ & $\begin{array}{c}\text { Not screened } \\
\text { No. }(\%) \\
\end{array}$ & $\mathrm{X}^{2}, \mathrm{df}, \mathrm{p}$ & Odds Ratio \\
\hline \multicolumn{5}{|l|}{ Level of schooling } \\
\hline Primary & $15(7)$ & $191(93)$ & \multirow{3}{*}{$\begin{array}{l}X^{2}=21.728 \\
d f=3\end{array}$} & \multirow[b]{3}{*}{$\mathrm{OR}=5.727$} \\
\hline Secondary & $26(23)$ & $87(77)$ & & \\
\hline Tertiary & $8(29)$ & $20(71)$ & & \\
\hline No formal education & $6(26)$ & $17(74)$ & \multirow[t]{2}{*}{$\mathrm{p}=0.000$} & \multirow[t]{2}{*}{$\mathrm{p}=0.000$} \\
\hline Total & $55(15)$ & $315(85)$ & & \\
\hline \multicolumn{5}{|l|}{ Religion } \\
\hline Roman Catholic & $20(15)$ & $116(85)$ & \multirow{3}{*}{$\begin{array}{l}X^{2}=7.926 \\
\mathrm{df}=2\end{array}$} & \multirow{3}{*}{$\begin{array}{l}\mathrm{O} R=0.739 \\
\mathrm{p}=0.228\end{array}$} \\
\hline Protestants & $27(13)$ & $184(87)$ & & \\
\hline Muslims & $8(35)$ & $15(65)$ & & \\
\hline Total & $55(15)$ & $315(85)$ & $\mathrm{p}=0.019$ & \\
\hline \multicolumn{5}{|l|}{ Main source of income } \\
\hline Farm produce & $26(11)$ & $201(89)$ & \multirow{2}{*}{$\begin{array}{l}\mathrm{X}^{2}=15.030 \\
\mathrm{df}=2\end{array}$} & \multirow{4}{*}{$\begin{array}{l}\mathrm{OR}=0.576 \\
\mathrm{p}=0.001\end{array}$} \\
\hline Business & $7(10)$ & $60(90)$ & & \\
\hline Employed/salaried & $22(29)$ & $54(71)$ & $\mathrm{p}=0.001$ & \\
\hline \multirow{2}{*}{\multicolumn{5}{|c|}{ Average monthly income (US\$) }} \\
\hline & & & & \\
\hline$\leq 25$ & $7(8)$ & $79(82)$ & \multirow{6}{*}{$\begin{array}{l}\chi^{2}=27.942 \\
\mathrm{df}=4 \\
\mathrm{p}=0.000\end{array}$} & \multirow{6}{*}{$\begin{array}{l}\mathrm{OR}=0.692 \\
\mathrm{p}=0.001\end{array}$} \\
\hline$>25-50$ & $14(10)$ & $125(90)$ & & \\
\hline$>50-100$ & $13(18)$ & $58(82)$ & & \\
\hline$>100-200$ & $15(43)$ & $20(57)$ & & \\
\hline$>200$ & $6(15)$ & $33(85)$ & & \\
\hline Total & $55(15)$ & $315(85)$ & & \\
\hline
\end{tabular}


Level of awareness on cervical cancer screening: From the data on the levels of awareness on cervical cancer, $53.8 \%$ of the women had heard about the condition while $46.2 \%$ of them had not (Figure 1 ).

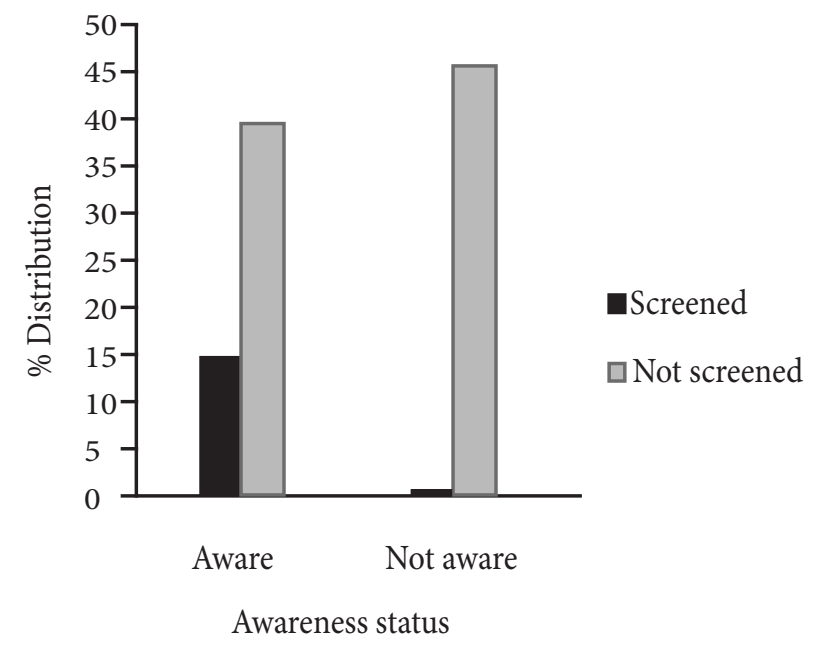

Figure 1: Levels of awareness about cancer of the cervix

Reasons for not being screened: Only 14.9\% of the respondents in the survey had been screened for cervical cancer. Those who had not been screened gave various reasons for not doing so, ranging from lack of information about screening (37\%), not getting services when they needed it $(1.4 \%)$ or not getting approval from partners among others (Table 2).
Table 2: Respondents reasons for not being screened

\begin{tabular}{ll}
\hline Reasons for not being screened $(\mathrm{n}=370)$ & $(\%)$ \\
\hline 1. No information & 37.3 \\
2. Didn't have enough time & 3.8 \\
3. Didn't get the services when needed them & 1.4 \\
4. Didn't think they were susceptible & 4.6 \\
5. Embarrassment of being examined in the & 12.0 \\
& \\
6. No No approval from their partners & 2.2 \\
7. Worried that they can be told they have & 9.2 \\
& cervical cancer \\
8. Hadn't thought about it & 14.6 \\
9. Screened & 14.9 \\
\hline Total & 100 \\
\hline
\end{tabular}

Decision making regarding health issues: A small group of the respondents had their partners to make decision for seeking cervical cancer screening services. Seventy three percent of the sampled women were the decision makers on when and where to go for health services, $20 \%$ had their partners deciding for them while $7 \%$ of the interviewed women had the decisions made by their parents or guardians (Table 3).

Table 3: Who makes decision on where and when to go to the health facility

\begin{tabular}{llllll}
\hline \multirow{2}{*}{ Variables $(\mathrm{n}=370)$} & $\begin{array}{l}\text { Screened } \\
\text { No. }(\%)\end{array}$ & $\begin{array}{l}\text { Not screened } \\
\text { No. }(\%)\end{array}$ & Total & $\chi^{2}, \mathrm{df}, \mathrm{p}$ & \multirow{2}{*}{ OR } \\
\hline Partner & $5(6.8)$ & $68(93.2)$ & & $\chi^{2}=6.908$ & \multirow{2}{*}{$\mathrm{OR}=0.448$} \\
Self & $43(15.9)$ & $228(84.1)$ & $\mathrm{df}=2$ & $\mathrm{p}=0.009$ \\
Parents/guardians & $7(26.9)$ & $19(73.1)$ & $\mathrm{p}=0.032$ & \\
\hline
\end{tabular}

\section{Discussion}

This was a descriptive study involving 370 women of reproductive age attending $\mathrm{MCH} / \mathrm{FP}$ clinics in public health facilities. Cervical cancer has a long precancerous period, usually taking more than 10 years to progress to invasive cancer. As a result, it is rare for cervical cancer to develop in women less than thirty years of age [8]. However the results in our study indicated that majority $(55.1 \%)$ of the women were below 30 years and $27 \%$ of them were not aware about cervical cancer screening services. There was no significant difference between age and marital status of the respondent and utilization of cervical cancer screening services, $(p=0.146$ for age $)$ and ( $p=0.938$ for marital status). Similar study in Malaysia indicated that knowledge and barriers towards cervical cancer screening among young women influenced the rate of screening [9].

From parity data, $47 \%$ of the women had 2-3 children and $27 \%$ had only one child. Multiparty is a risk to many maternal conditions and it is one of the predisposing factors to development of cervical cancer [11]. Such risks were observed in women suffering from Human Papilloma Virus (HPV) in which infected women who had five or more children had a three-fold increase in the risk of cervical cancer compared to women with no children [10]. In the current study parity did not have significant difference in relation to respondents uptake of the available screening services $(p=0.857)$. The results are similar to those of a study on presentation and health care seeking behaviour of patients with cervical cancer seen at Moi Teaching and Referral Hospital, Eldoret Kenya, where parity had no influence on screening for cervical cancer [11].

Level of education was found to be an important determinant in health seeking behaviour among many communities [17]. In our study the level of education significantly influenced the uptake of availed cervical cancer screening services $(\mathrm{P} \leq 0.0001)$, an observation which was also reported among women in rural India 
[12] and other low resource settings [13]. Educated people are able to perceive their health and health related problems better than non educated ones. In many cases uneducated or semi educated people do not access health services despite being economically stable due to various misconceptions in favour of some unconventional or traditional therapies [14]. Such are the challenges that could be addressed by strengthening and expanding programs addressing women/girl child education.

Studies conducted elsewhere indicated that depending on the conviction of the various teachings, the religion of the woman could positively or negatively influence the levels of utilization of the availed health services $[12,15,16]$, religion may influence the human behaviour for seeking cervical cancer screening services but our study did not show any significant difference between the respondent's religion and the willingness to use VIA/VILI services, $(P \leq 0.228)$. Cultural and religious beliefs, such as the values placed on premarital virginity and modesty could contribute to reluctance to seek health services. A study on determinants influencing uptake of Pap smear among Indian women did not find any statistical significant relationship between their religion and the Pap smear tests as a method for cervical screening [12]. On the other hand, women of Catholic denomination were reported to be less likely to receive proper health care in reproductive health services in rural Vietnam [15]. In USA, immigrant muslim women had low rates of health services utilization, more so in preventive care such as, mammograms, general breast examinations and cervical cancer screening [16].

In regard to socioeconomic factors, majority (61.4\%) of the women in this study were unemployed and the main source of income was domestic farming, a factor that significantly affected the rates of utilization of VIA/ VILI services $(p=0.001)$. Low utilization of health services in developing countries was associated with low income which could result from little or no attention being given to individual's health care needs due to financial constraints. Women issues sometimes become secondary and are ignored by the household heads as they struggle to cater for the basic needs of their families [17]. Majority (52\%) of the respondents were supported by their husbands/partners as the main income earners. However, there was no significant difference ( $\mathrm{p}=$ 0.409) between the main income earner and the client's willingness to seek cervical cancer screening services in this study. In a study on men's involvement in promoting reproductive health in South Africa, male partners were a factor in determining the uptake of the services as he was the one to provide the funds for transport and the hospital fee [18]. In most communities the head of the family who is usually the main income earner and in most cases the male partner decides who, when and where to seek health care services. Elsewhere, report on personal factors that could influence the uptake of cervical cancer screening services indicated that the rates were lower amongst women who were older, reliant on welfare, obese, current smokers, those who reported childhood sexual abuse, and those with anxiety symptoms [19].

A study on health behavior and health education theory, research, and practice, [20] emphasized the importance of community readiness and participation in increasing cervical screening services uptake in a given community. Thirty five percent of the respondents stated that they had never heard people discussing cervical cancer implying that the level of engagement of the community in discussing cervical cancer was low. Encouraged, such an approach would go a long way in breaking the psychosocial- barriers and may play an important role towards success in the a screening programme [21].

The health centres were not well equipped in terms of materials, reagents and equipments. The reagents were not replenished on time and in all the health centres the cryotherapy machine, which is used for treatment of the appropriate lesions, were not working. This affected the single visit approach because the VIA positive clients could not be treated at the site or the same day. Lack of some of essential supplies and equipment also meant missed opportunities could arise [22]. For the screening services coverage to increase, the number of the staff trained on VIA/VILI should also increase [22].

\section{Conclusions}

The level of awareness on cervical cancer prevention among eligible clients in Kitui County Kenya was low $(53.8 \%)$ compared to national target of over $70 \%$. Awareness on existence of cervical cancer and its prevention services, level of education, main source of income and average monthly income significantly influenced VIA/VILI cervical cancer screening services uptake. Cultural factors such as who decides on matters regarding health in the family also influenced the uptake of the screening services. Clients age, marital status, parity, religion and main income earner were not significantly associated with utilization of VIA/VILI screening services. The public health facilities were not adequately staffed and equipped to handle the VIA/VILI cervical cancer screening services effectively. This had an influence in the overall uptake of VIA/VILI cervical cancer screening services. It is thus recommended that health care providers and other stake holders should increase awareness on available methods of screening and importance of being screened for cervical cancer and communities should empower women educationally and economically.

\section{Declaration}

The authors declare that they have no competing interests. 


\section{Acknowledgements}

We are grateful to the medical and nursing officer in charges of the public health facilities (Kitui Subcounty Hospital, Miambani, Kisasi and Mbitini Health Centres) in which the study was conducted and also the respondents who made this study a success.

\section{References}

1. International Agency for Research on Cancer (IARC), Global Cancer (2012) Estimated Cancer Incidence mortality and prevalence worldwide in 2012.

2. World Health Organization (2013) WHO Guidance note, comprehensive cervical cancer prevention and control: a healthier future for girls and women.

3. WHO (2010) Strengthening cervical cancer prevention and control.

4. WHO/ICO (2010). Information Centre on HPV and Cervical cancer (HPV Information Centre). Human Papillomavirus and Related Cancers in Kenya. Summary Report 2010.

5. Sellors J, Muhombe K and Castro W. Palliative care for women with cervical cancer: A Kenya Field Manual. Seattle, WA: PATH (2004).

6. Ministry of Public Health and Sanitation/Ministry of Medical Services (MoPHS/MoMS) (2012): National Guidelines for Prevention and Management of Cervical, Breast and Prostate Cancers.

7. Ministry of Health, Government of Kenya, National Reproductive Health Policy 2007.

8. World Health Organization (2006). Comprehensive Cervical Cancer Control: A Guide to Essential Practice. Geneva: WHO.

9. Redhwan Ahmed Al Nagger, Low WY and Isa ZM. Knowledge and barriers towards cervical cancer screening among young women in Malaysia Asian Pacific. Asian Pacific J Cancer Prev. 2010; 11: 867-873.

10. Munoz N, Moreno V, Xavier B, Chris J, Keerti V, et al. Role of parity and human papillomavirus in cervical cancer: The IARC multicentric case-control study. Lancet. 2002; 359(9312): 1093-1101.

11. Were E, Nyaberi $Z$ and Buziba N. Perceptions of risks and barriers to cervical cancer screening at Moi Teaching and Referral Hospital (MTRH) Eldoret, Kenya. Afr J Health Sci. 2011; 11(1): 58-64.

12. Singh $S$ and Badaya $S$. Factors influencing uptake of cervical cancer screening among women in India: A hospital based pilot study. J Comm Med Health Educ. 2012; 2:157.
13. Bingham A, Bishop A, Coffey P, Winkler J, Bradley J, Dzuba I and Agurto I. Factors affecting utilization of cervical cancer prevention services in lowresource settings. Salud Publica Mex. 2003; 45 (suppl 3):S408-S416.

14. Wamai RG. The health system in Kenya: Analysis of the situation and enduring challenges. JMAJ. 2009; 52(2): 136.

15. Toan NV, Hoa HT, Trong PV, Hojer B, Persson LA and Sundstrom K. Utilisation of reproductive health services in rural Vietnam; are there equal opportunities to plan and protect pregnancies? J Epidemiol Comm Health. 1996; 50:451-455 doi:10.1136/jech.50.4.451.

16. Matin M and LeBaron S. Attitudes toward cervical cancer screening among muslim women: a pilot study. Women Health. 2004; 39(3):63-77.

17. Gupta I, Joe W and Rudra S. Demand side financing in health: How far can it address the issue of low utilization in developing countries? World Health Report (2010) Background Paper, No. 27.

18. Tod MM Maja and Litt Phil. Men's involvement in promoting reproductive health. Women and health learning package developed by The Network: TUFH Women and Health Taskforce Second edition, September 2006.

19. Olesen SC, Butterworth P, Jacomb P and Tait RJ. Personal factors influencing use of cervical cancer screening services: epidemiological survey and linked administrative data address the limitations of previous research. BMC Health Services Res. 2012; 12:34.

20. Glanz KB, Rimer K and Viswanath K, eds. (2008). Health behavior and health education: Theory, research, and practice. 4th ed. San Francisco: Wiley.

21. Flora FT, Sheona MM, Sekikubo M, Biryabarema $\mathrm{C}$, et al. Understanding the role of embarrassment in gynecological screening: a qualitative study from the ASPIRE cervical cancer screening project in Uganda. Br Med J Open. 2014; 4: 4 e004783.

22. Sudenga SL, Rositch F, Walter A and Jennifer S. Knowledge, Attitudes, Practice and perceived risk of cancer of the cervix among Kenyan women. Intern J Gynecol Cancer. (Impact Factor: 1.95). 06/2013; 23(5):895-899. 